\title{
Estimation of optic disc size using indirect biomicroscopy
}

\author{
Simon Ruben
}

\begin{abstract}
The use of the 90 dioptre fundus lens in conjunction with slit-lamp biomicroscopy as a method of estimating optic size was evaluated in a series of 37 patients. The measurements taken from the Haag-Streit slit-lamp were compared with values obtained planimetrically in order to assess a conversion factor and also the reliability of the method. This technique is a quick and easy method of obtaining an estimate of optic nerve head size in the clinic, but cannot replace more accurate methods of optic disc planimetry.
\end{abstract}

(Br F Ophthalmol 1994; 78: 363-364)

It would be useful in clinical ophthalmic practice to be able to differentiate between small and large optic discs without having to resort to fundus photography and time consuming planimetric methods. Many patients with high cup-disc ratios are considered to be at risk from developing glaucomatous visual loss and are followed up in glaucoma clinics indefinitely on account of this finding, often despite normal intraocular pressures and visual fields. More recent evidence points towards the use of neuroretinal rim area as a more reliable index of glaucoma risk. ${ }^{12}$ Jonas and Quigley have both shown a correlation between nerve fibre count and disc $\operatorname{size}^{34}$ which means that even with high cup-disc ratios the actual amount of neural tissue is likely to be within normal limits. ${ }^{46}$

Other methods of optic disc estimation have been described including recently a technique using the indirect ophthalmoscope in conjunction with a calliper device. ${ }^{5}$

Here, a simple and very quick method of estimating the approximate diameter of the optic nerve head is described. This utilises the method of indirect biomicroscopy in conjunction with the 90 dioptre fundus lens and can if necessary be done without mydriasis.

\section{Patients and methods}

Thirty seven eyes of 37 patients were investigated initially in order to determine the calibration. All patients had optic discs considered to be within normal limits clinically and had normal visual fields. Patients with refractive errors greater than plus or minus 5 dioptres were excluded.

The optic disc was viewed in the normal way

Glaucoma Unit,

Moorfields Eye Hospital, City Road, London EC1V 2PD

$S$ Ruben

Correspondence to:

Mr S Ruben, Glaucoma Unit, Moorfields Eye Hospital, City Road, London ECIV 2PD.

Accepted for publication

10 January 1994 the slit beam is then read off the scale of the Haag-Streit slit-lamp to the nearest $0.5 \mathrm{~mm}$. However, this measurement obviously does not relate to the actual size of the disc in millimetres, and a correction has to be made to account for this. In order to investigate the relation between the readings made in this way with those obtained by a more conventional planimetric method the results were compared with disc diameters measured planimetrically from optic disc photographs.

Patients underwent full mydriatic fundus photography using a Canon 60-U retinal camera. Photographs were analysed with a computer assisted planimetric device which utilises a modified Littman formula to allow for the Canon retinal camera (Discdata, Thot Informatique, Pr Bechetoille, Angers, France). This system has been shown to have good intraobserver variation. ${ }^{7}$ Measurements of vertical diameter were calculated using this system. The vertical height measurement obtained was used for comparison with the readings taken with the $90 \mathrm{D}$ lens at the slit-lamp.

Each of the two measurements were taken independently without knowledge of the other measurement. All observations and measurements were made by the same person (SR).

\section{Results}

The results of the estimated disc diameter using the $90 \mathrm{D}$ lens are plotted against the planimetrically determined diameters in Figure 1. There was a highly significant correlation between the two sets of results (Pearson's correlation coefficient $r=0.82, p<0.000001)$. From this plot it is possible to determine a conversion factor for the estimated disc diameter obtained with the $90 \mathrm{D}$ lens (equation of regression line: $\mathrm{Y}=1 \cdot 17 \mathrm{X}+0 \cdot 24)$.

Slit-lamp recordings of more than $1.4 \mathrm{~mm}$ correspond to a planimetrically measured size more than or equal to $1.9 \mathrm{~mm}$. Using these parameters, $89 \%$ of discs estimated to be $1.9 \mathrm{~mm}$ or larger (that is, give a reading $\geqslant 1.4 \mathrm{~mm}$ ) at the slit-lamp are found to measure $\geqslant 1.9 \mathrm{~mm}$ planimetrically. On the other hand, $100 \%$ of discs estimated to be smaller than $1.9 \mathrm{~mm}$ (giving a reading $<1.4$ units at the slit-lamp) are found also to be smaller than $1.9 \mathrm{~mm}$ planimetrically.

A nomogram can be constructed (as in Fig 2) in neuroretinal rim surface. Instructing the patient reliable measurement in millimetres.

to fixate on the ear of the examiner (right ear for In order to establish the reproducibility and examining the right eye) brings the optic nerve precision of this technique 10 further optic discs head into the centre of view. The height of the slit were examined and four estimates recorded for beam can then be adjusted until it coincides with each one. The results are shown in Table 1. It can the disc edges. The width of the slit beam could be seen that the standard deviations for repeat have been used in a similar fashion. The size of measurements are small and that the estimated 


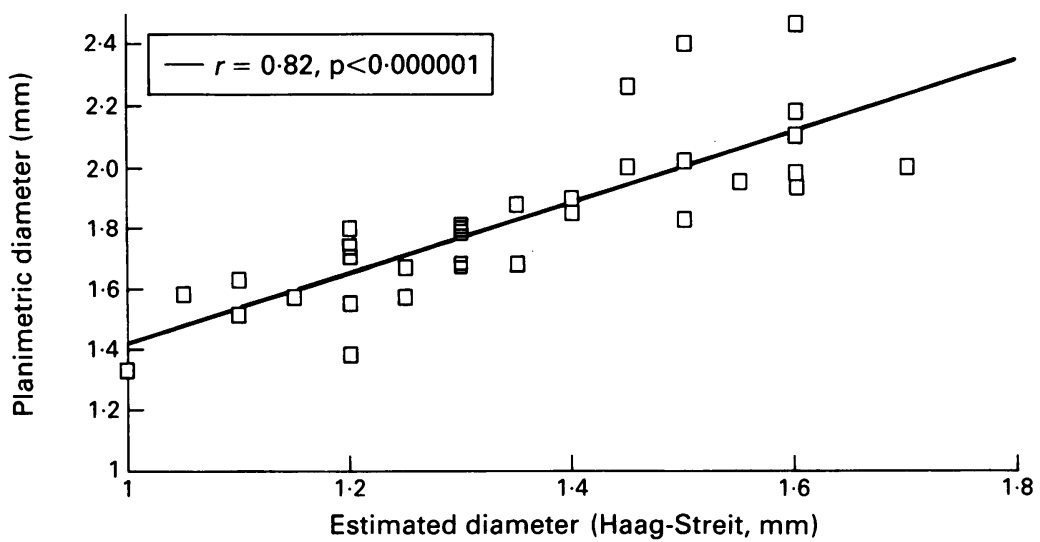

Figure 1 Scattergram of planimetrically measured diameters plotted against diameters estimated using $a$ $90 \mathrm{D}$ lens.

Figure 2 Nomogram for conversion of Haag-Streit units into corresponding millimetre measurements.

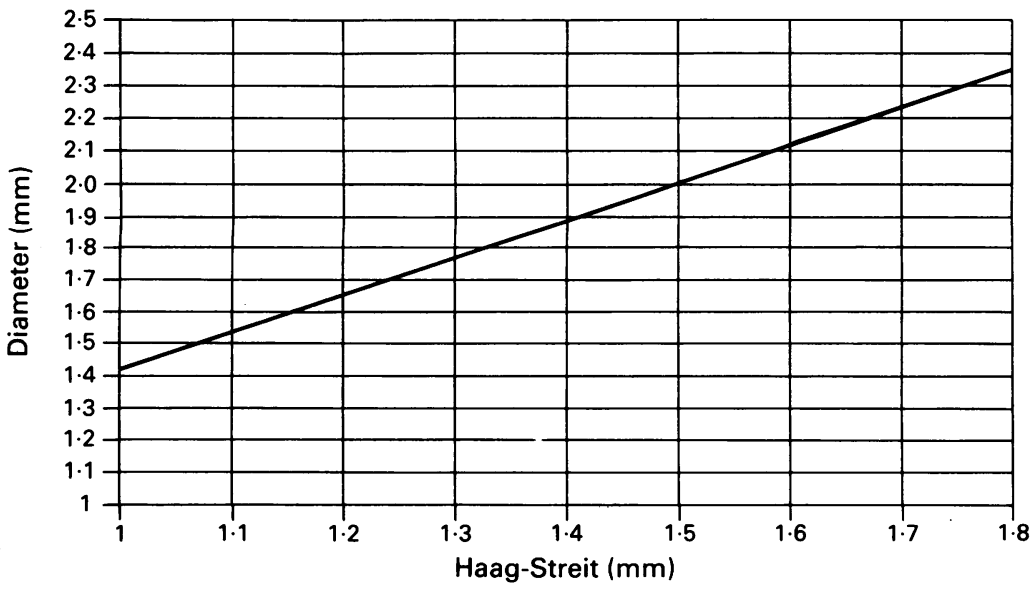

values are in close agreement with those measured planimetrically. This method appears to give a reliable estimate of disc size with adequate precision to allow the examiner to decide whether an optic disc is large or small.

\section{Discussion}

It can be seen from these results that it is possible to estimate quickly the size of optic discs in the clinic. Optic discs that are estimated at over $1.4 \mathrm{~mm}$ on the Haag-Streit slit-lamp are very likely to be more than $1.9 \mathrm{~mm}$ in size.

Previous investigators have reported a variety of methods for estimating optic disc size utilising direct ophthalmoscope, indirect ophthalmoscope, and the Goldmann contact lens at the slitlamp. ${ }^{39}$ These methods depend on graticules and/or conversion constants based on the lens used, and refraction of the eye. With both direct and indirect techniques refractive error influences the size of the image unless the lens coincides with the anterior focus of the eye ${ }^{8}$ (which is very unlikely). The method described here requires no specialist equipment and is very quick to perform.

It has been shown that neuroretinal rim area increases with increasing disc size despite an increase in cup-disc ratio. ${ }^{11}$ Large discs with high cup-disc ratios are therefore likely to represent the upper end of the normal range and be considered 'physiological' in nature, as long as there are no other features to suggest abnormality such as the ovalness of cupping, focal rim defects, or vascular changes.

There is still some controversy over the significance of large discs. Chi et al support the

Table 1 Mean and standard deviation of four repeat estimates of vertical disc diameter in 10 eyes with measurements made planimetrically for comparison

\begin{tabular}{rlll}
\hline & $\begin{array}{l}\text { Vertical disc } \\
\text { diameter estimated } \\
\text { using 90 D lens } \\
\text { (from nomogram) } \\
\text { (mean of four } \\
\text { readings) }\end{array}$ & $S D$ & $\begin{array}{l}\text { Vertical disc } \\
\text { diameter } \\
\text { measured } \\
\text { planimetrically }\end{array}$ \\
\hline 1 & 1.77 & 0.098 & 1.8 \\
2 & 1.93 & 0.03 & 1.95 \\
3 & 1.72 & 0.057 & 1.68 \\
4 & 1.8 & 0.035 & 1.88 \\
5 & 1.74 & 0.035 & 1.62 \\
6 & 1.65 & 0.094 & 1.8 \\
7 & 1.78 & 0.057 & 1.65 \\
8 & 1.85 & 0.057 & 1.85 \\
9 & 1.92 & 0.055 & 1.88 \\
10 & 1.69 & 0.03 & 1.8 \\
\hline
\end{tabular}

view that larger discs predispose to glaucoma, based on the observation that black patients with glaucoma had significantly larger discs than matched white patients. ${ }^{12}$ However there may be other racial differences to account for this finding. This view is not supported by Jonas et al who found no correlation between disc size and severity of glaucoma, but propose that smaller discs are at greater risk because of their smaller number of nerve fibres. ${ }^{13}$

A similar estimation of disc size could be performed using the $78 \mathrm{D}$ lens, but its greater magnification gives larger values for the readings taken from the Haag-Streit slit-lamp. The distance that the lens is held from the eye does not appear to be critical (as shown by the reproducibility) as in other techniques as the measured length of the slit beam remains relatively constant as long as the disc remains in focus.

The technique described here is a quick and easy method for estimating optic disc size in the clinical setting and may help in making decisions concerning the follow up of patients with large cup-disc ratios or of patients with discs of asymmetrical size. It is not intended to give precise measurements of disc parameters nor to replace other methods used for accurate analysis of the optic disc.

1 Airaksinen PJ, Drance SM, Schulzer M. Neuroretinal rim area in early glaucoma. Am $\mathcal{F}$ Ophthalmol 1985; 99: 1-4.

2 Tuulonen $A$. The morphological pattern of early glaucomatous damage. Current Opinion in Ophthalmology 1993; 4: 29-34.

3 Jonas JB, Schmidt AM, Muller-Bergh JA, SchlotzerSchrehardt UM, Naumann GOH. Human optic nerve fibre count and optic disc size. Invest Ophthalmol Vis Sci 1992; 33: 2012-8.

4 Quigley HA, Brown AE, Morrison JD, Drance SM. The size and shape of the optic disc in normal human eyes. Arch Ophthalmol 1990; 108: 51-7.

5 Montgomery DMI. Measurement of optic disc and neuroretinal rim areas in normal and glaucomatous eyes. A new retinal rim areas in normal and glaucomatous
clinical method. Ophthalmology 1991; 98: 50-9.

6 Bottoni FG, Gonnella PM, Porta AS, Consalez GG. Neuroretinal rim area in normal eyes: a study on a randomised group of 30 subjects. Ophthalmologica 1989; 198: 40-5.

7 Sturmer J, Poinoosawmy D, Broadway DC, Hitchings RA Intra- and inter-observer variation of optic nerve head measurements in glaucoma suspects using disc data. In Ophthalmol 1992; 16: 221-3.

8 Franceschetti A, Bock RH. Megalopapilla: a new congenital anomaly. Am f Ophthalmol 1950; 33: 227-34.

9 Beuchat L, Safran AB. Optic nerve hypoplasia: papillary diameter and clinical correlation. $\mathcal{F}$ Clin Neuro-ophthalmol 1985; 5: 249-53.

10 Britton RJ, Drance SM, Schulzer M, Douglas GR, Manson DK. The area of the neuroretinal rim of the optic nerve in DK. The area of the neuroretinal rim of the optic
normal eyes. Am f Ophthalmol 1987; 103: 497-504.

11 Caprioli J, Miller JM. Optic disc rim area is related to disc size in normal subjects. Arch Ophthalmol 1987; 105: 1683-5.

12 Chi T, Ritch R, Stickler D, Pitman B, Tsai C, Hsieh FY. Racial differences in optic nerve head parameters. Arch Ophthalmol 1989; 107: 836-9.

13 Jonas JB, Fernandez C, Naumann GOH. Correlation of the optic disc size to glaucoma susceptibility. Ophthalmology 1991; 98: 675-80. 